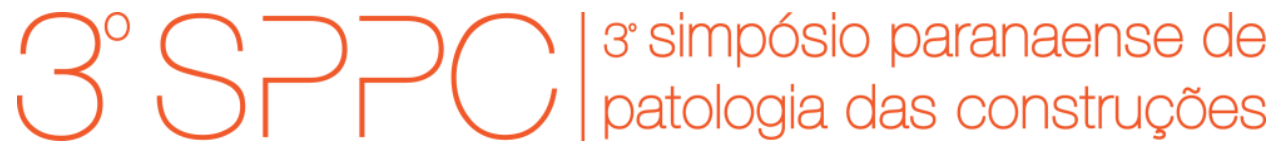

ISSN 2526-7248 artigo n. 3SPPC1001, pp. 1-12, 2018

\title{
Manifestações patológicas e imperfeições construtivas: estudo de caso em obra pública na Cidade de Toledo-PR
}

\author{
FIGUR, Neusa Eliana ${ }^{1}$; FURLAN, Gladis Cristina ${ }^{2}$ \\ ${ }^{1}$ Mestranda, Universidade Federal do Paraná, neusafigur@hotmail.com \\ ${ }^{2}$ Mestre, Universidade Tecnológica Federal do Paraná, furlan.gladis@gmail.com
}

Resumo: As falhas construtivas, comumente encontradas nas construções civis no Brasil, dão origem a uma série de implicações patológicas. Estas apresentam, em curto prazo, no pós entrega e ocupação, problemas que comprometem a funcionalidade, o conforto, a estética e, em muitos casos, até mesmo a segurança dos ocupantes. A presente pesquisa propõe, por meio de um estudo de caso, verificar como a execução das etapas construtivas sem observar às normas técnicas podem ocasionar falhas, que, por sua vez, aparecem com frequência em edifícios públicos. Foram realizadas visitas in loco em uma obra pública na cidade de Toledo-PR, do início ao fim da construção, e registradas fotografias das manifestações patológicas. Estas, posteriormente, de acordo com sua tipologia, tiveram suas causas identificadas com base em consulta à pesquisas de autores consagrados na área em estudo e investigação do processo executivo empregado na obra. Verificou-se que as manifestações patológicas provêm, de forma absoluta, das falhas cometidas pela mão de obra ruim e má qualidade dos materiais, evidenciando a ineficiência do critério de contratação de obras públicas no Brasil, o de menor preço.

Palavras chave: Manifestações patológicas, Qualidade, Obras Públicas.

Abstract: The constructive failures, commonly found in civil constructions in Brazil, generate a series of pathological implications. Those present, in the short term, after handing over and occupation, problems that compromise functionality, comfort, aesthetics and, in many cases, even occupancy safety. The present research intends, by the means of a case study, to verify how the execution of the constructive stages without observation of the technical norms can cause failures, that, by themselves, appear frequently in public buildings. On-site visits were carried out in a public construction site in the city of Toledo-PR and photographs of pathologies were taken which. These, afterwards, accordingly to their typology, had their causes identified, based on consultation to researches of consecrated authors in the study field and investigation of the executive process employed. It was verified that the pathologies appear, in absolute terms, from the errors committed by the poor labor and bad quality of the materials, showing the inefficiency of the criterion of contraction of public works in Brazil, wich is the one of lower price.

Keywords: Pathologies, Quality, Public Works. 


\section{Introdução}

O processo de licitações públicas no Brasil é regulamentado atualmente pela Lei 8.666 de junho de 1993, por meio de concorrência pública. Esta estabelece o tipo de licitação, ou seja, o critério a ser considerado pelo administrador quando do julgamento das propostas para execução de determinada obra. Segundo Fabricio [1], de maneira geral, a licitação de menor preço é a que prevalece, ou seja, as propostas, independentemente de sua qualidade, mas estando em conformidade com os requisitos mínimos do edital, serão classificadas conforme a proposta, vencendo aquela de menor preço.

O mesmo autor questiona se o critério do menor preço vem contribuindo para que a contratação de produtos, obras e serviços sejam eficientes e de qualidade. "Se uma empresa trabalha com preço ruim, ele não tem como manter profissionais de alta qualidade para elaborar um projeto que atenda todos os aspectos de uma determinada obra. Isso contrapõe preço e qualidade", afirma Maurício de Lana, membro-diretor da Associação Brasileira de Consultores de Engenharia (ABCE) [2].

Neste contexto, o presente trabalho foi baseado em um estudo de caso, considerando problemas patológicos detectados em uma edificação pública, ainda em fase de construção, na cidade de Toledo-PR.

\section{Metodologia}

Inicialmente, foi realizada uma revisão bibliográfica a respeito das manifestações patológicas nas construções. Buscou-se em bibliografias nacionais e internacionais (livros, artigos e periódicos) e arquivos eletrônicos, fundamentos para 0 desenvolvimento e sustentação do tema.

Paralelamente à revisão bibliográfica, foram levantados os problemas patológicos da obra em estudo. Para isto foram realizadas visitas in loco. Os dados coletados são sigilosos e foram protegidas a identificação tanto da empresa responsável pela execução assim como a obra acompanhada.

Para a identificação das manifestações patológicas, adotou-se como metodologia a inspeção visual e o levantamento fotográfico. Foram investigados ainda, os processos executivos que vieram a ocasionar tais falhas.

Nas análises feitas por meio da inspeção visual da edificação, buscou-se irregularidades como: trincas, infiltração, eflorescências, corrosão. Posteriormente, estes dados foram analisados, sendo executado seu diagnóstico onde foram identificadas as causas para a ocorrência das manifestações patológicas.

\section{Resultados e discussões}

De modo geral, como lembram lantas [3] e Oliveira [4], as manifestações patológicas construtivas apresentam manifestações externas que permitem identificar sua natureza, origem e os mecanismos envolvidos no seu desenvolvimento, além de indicar as atividades em que ocorrem as falhas do 

3SPPC1001, pp. 1 - 12, 2018. DOI: 10.4322/2526-7248.001

sistema de controle de qualidade. Além disso, segundo Helene [5], os problemas patológicos possuem característica evolutiva e tendência a agravar-se com o tempo, ou ainda, possibilitarem o desenvolvimento de outros problemas associados ao inicial. Em vista destes conceitos, segue-se ao apontamento das principais anomalias e defeitos encontrados na obra em estudo.

\subsection{Anomalias}

Durante a investigação dos problemas em obra, foram identificadas diferentes anomalias, sejam elas: manchas, fissuras, corrosão de armaduras, ninhos de concretagem (segregação dos materiais constituintes do concreto), dentre outras. Os itens a seguir apresentam as principais manifestações patológicas identificadas nos diferentes componentes da edificação (parede de alvenaria, revestimentos argamassados e cerâmicos, pisos, forro, vigas e lajes), bem como o processo executivo que deu lhe causa.

\subsubsection{Fissuras em alvenaria de vedação em bloco cerâmico}

Cargas verticais de compressão em paredes de alvenaria ocasionam fissuras tipicamente verticais, devido aos esforços de tração transferidos aos tijolos pelo atrito com a junta de argamassa (Fissura tipo 2). Por outro lado, em paredes com aberturas, sobrecargas verticais geram fissuras inclinadas nos vértices dos vãos como as fissuras do tipo 1. Já as fissuras verticais na região sob o peitoril, segundo Thomaz [6], surgem devido ao fato de tensões diferenciadas, transmitidas ao solo em paredes com aberturas, provocar flexão negativa dos peitoris, ou seja, as paredes nos peitoris transmitem cargas menores que as laterais das janelas.

Tem-se ainda, que os vãos na alvenaria que recebem janelas e portas, são regiões de grande concentração de tensões [6]. Assim sendo, as tensões predominantemente verticais nestas áreas, tornam-se propícias ao aparecimento de fissuras verticais próximas à extremidade da esquadria ou exatamente nas extremidades superiores ou inferiores da mesma (Fissuras tipo 2). A ocorrência deste tipo de fissura é influenciada ainda, segundo Thomaz [6], pela qualidade e resistência dos materiais constituintes das alvenarias, pois a ruptura por esmagamento ocorre devido à incapacidade do material em resistir às solicitações de compressão.

Outro fator identificado em obra que teve contribuição na evolução de tais fissuras está na não execução das juntas verticais em paredes de alvenaria, chamadas também de "juntas secas", as quais diminuem a capacidade de redistribuição das tensões desenvolvidas nas paredes e resulta em prejuízo à resistência ao cisalhamento [7].

Já as fissuras com a tipologia 3, estão associadas a uma deformação total externa do composto de cimento e é influenciada por um conjunto de fatores, dentre eles, a principal causa, segundo Duarte [8], é a perda de água da argamassa de cimento. 0 volume ocupado inicialmente pelo material no estado plástico diminui conforme as condições ambientais de temperatura e umidade e a evolução da matriz cimentícia, ou seja, com a evaporação da água, a argamassa de cimento retrai deixando espaços vazios, os quais caracterizam as fissuras na superfície da mesma [9]. 
FIGUR, N.E.; FURLAN, G.C., MANIFESTAÇÃO DE PATOLOGIAS E IMPERFEIÇÕES CONSTRUTIVAS: ESTUDO DE CASO EM OBRA PÚBLICA NA CIDADE DE TOLEDO-PR. $3^{\circ}$ Simpósio Paranaense de Patologia das Construções (30 SPPC), artigo 3SPPC1001, pp. 1 - 12, 2018. DOI: 10.4322/2526-7248.001

\section{Tabela 1: Fissuras em paredes de alvenaria}

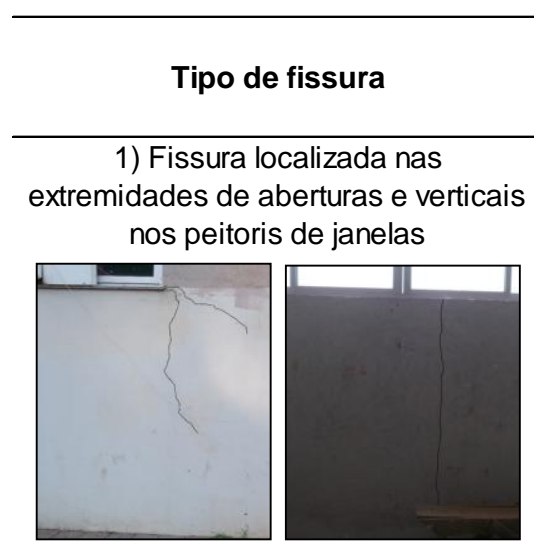

2) Fissuras verticais em paredes sem aberturas e/ou próximo de aberturas
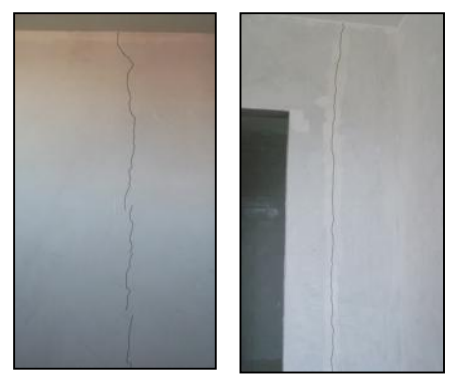

\section{Investigação do processo construtivo em desacordo com as recomendações técnicas da ABNT}

Fechamento de alvenaria sem a execução de vergas e contra vergas: NBR 8545: 1984
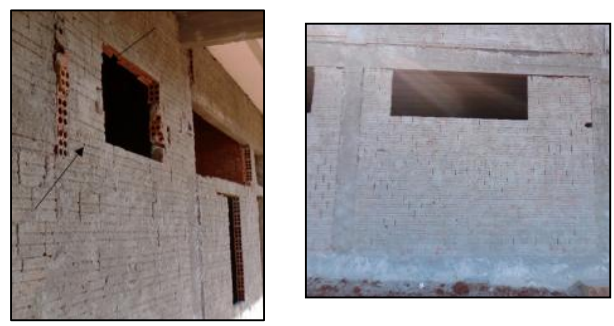

Blocos cerâmicos de baixa qualidade, apresentando trincas e quebras (NBR 15270: 2005) além da não execução de juntas verticais no assentamento da alvenaria (NBR 8545:1984).
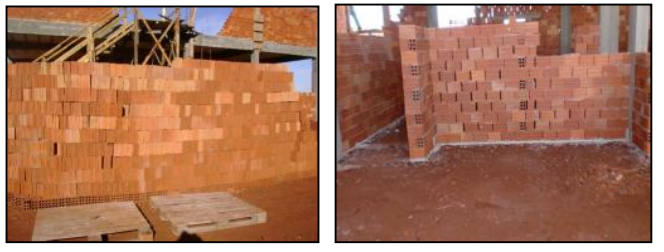

Tipo de fissura

3) Fissura mapeada

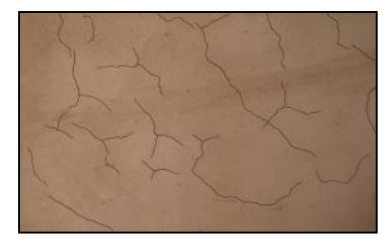

4) Fissura horizontal no encontro de viga e alvenaria

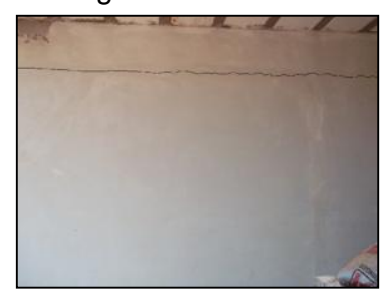

5) Fissura vertical no encontro entre pilar de concreto armado e parede de alvenaria

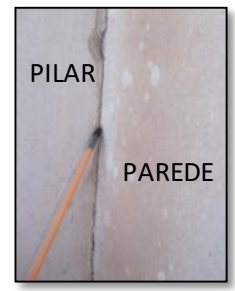

Investigação do processo construtivo em desacordo com as recomendações técnicas da ABNT

Retração da argamassa de revestimento: não realização de ensaios para verificação da umidade dos materiais (areia: NBR 9775:2011) resultando em

misturas com excesso de água e ainda, não umidificação da camada de substrato de modo a impedir a absorção de excessiva de água pelo mesmo (NBR 7200:1998).

Deficiência na execução do encunhamento de paredes (NBR 8545:1984)

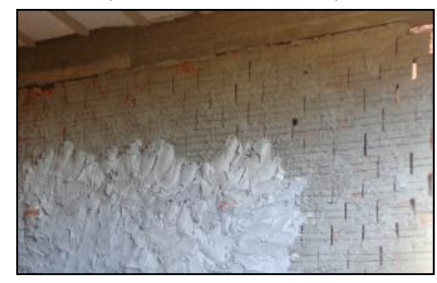

Ausência de encabeçamento dos blocos e não emprego de engastamento com barra de aço ("ferro cabelo") (NBR 8545:1984).

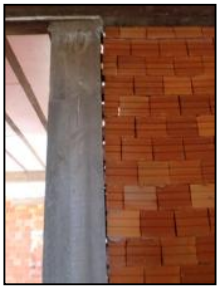



3SPPC1001, pp. 1 - 12, 2018. DOI: 10.4322/2526-7248.001

Por outro lado, um dos fatores que pode provocar fissuras localizadas logo abaixo de elementos de concreto armado, como é o caso de vigas (Tipo 4), é o recalque plástico do concreto, que, na execução precoce do encunhamento da parede, logo após a concretagem da viga, provoca o abatimento da alvenaria recém-construída, resultando no desprendimento da parede do componente superior [6].

As fissuras por deficiência de amarração entre pilar e alvenaria (Tipo 5), originam-se pela movimentação da alvenaria ligada a outros fenômenos, como por exemplo, variação térmica, retração, recalque [10], ou ainda, conforme Thomaz [6], por expansão da alvenaria devido à absorção de umidade. Em outras palavras, quando a solicitação causada pela movimentação encontra o plano de fraqueza da deficiência de amarração, surgem fissuras.

Observou-se ainda, que determinadas manifestações patológicas apresentadas na (Tabela 1), desencadearam o desenvolvimento de outras manifestações como mostra a (Fig. 1), onde fissuras nos cantos de janelas e trincas na interface viga/alvenaria possibilitaram o desenvolvimento de pontos localizados de infiltração, e ainda, no caso das trincas horizontais na interface viga/alvenaria, 0 desplacamento de revestimento cerâmico em fachadas aliada a não execução de junta de movimentação do revestimento como recomendado pela NBR 8214: 1983.
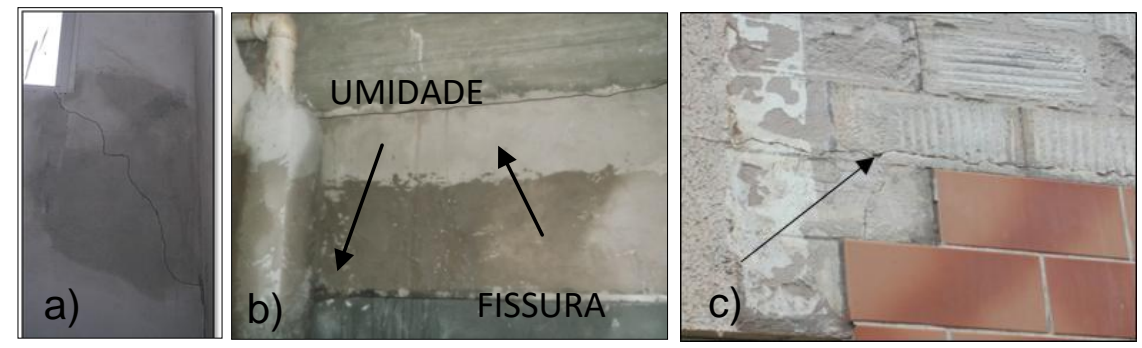

Figura 1: Problemas associados ao inicial. a) Infiltração em cantos de janelas b) Infiltração na interface viga/parede c) Desplacamento de revestimento cerâmico

\subsubsection{Manchas e eflorescências}

A não execução das juntas verticais na alvenaria, aliado a prováveis falhas na impermeabilização do reboco da fachada e o desenvolvimento de trincas por retração da argamassa de revestimento, deixam caminho livre para a passagem da água resultando em manchas de infiltração em paredes e rejuntes de revestimento cerâmico. 
FIGUR, N.E.; FURLAN, G.C., MANIFESTAÇÃO DE PATOLOGIAS E IMPERFEIÇÕES CONSTRUTIVAS: ESTUDO DE CASO EM OBRA PÚBLICA NA CIDADE DE TOLEDO-PR. $3^{\circ}$ Simpósio Paranaense de Patologia das Construções (30 SPPC), artigo 3SPPC1001, pp. 1 - 12, 2018. DOI: 10.4322/2526-7248.001

Tabela 2: Manchas e eflorescências em revestimentos argamassados e cerâmicos

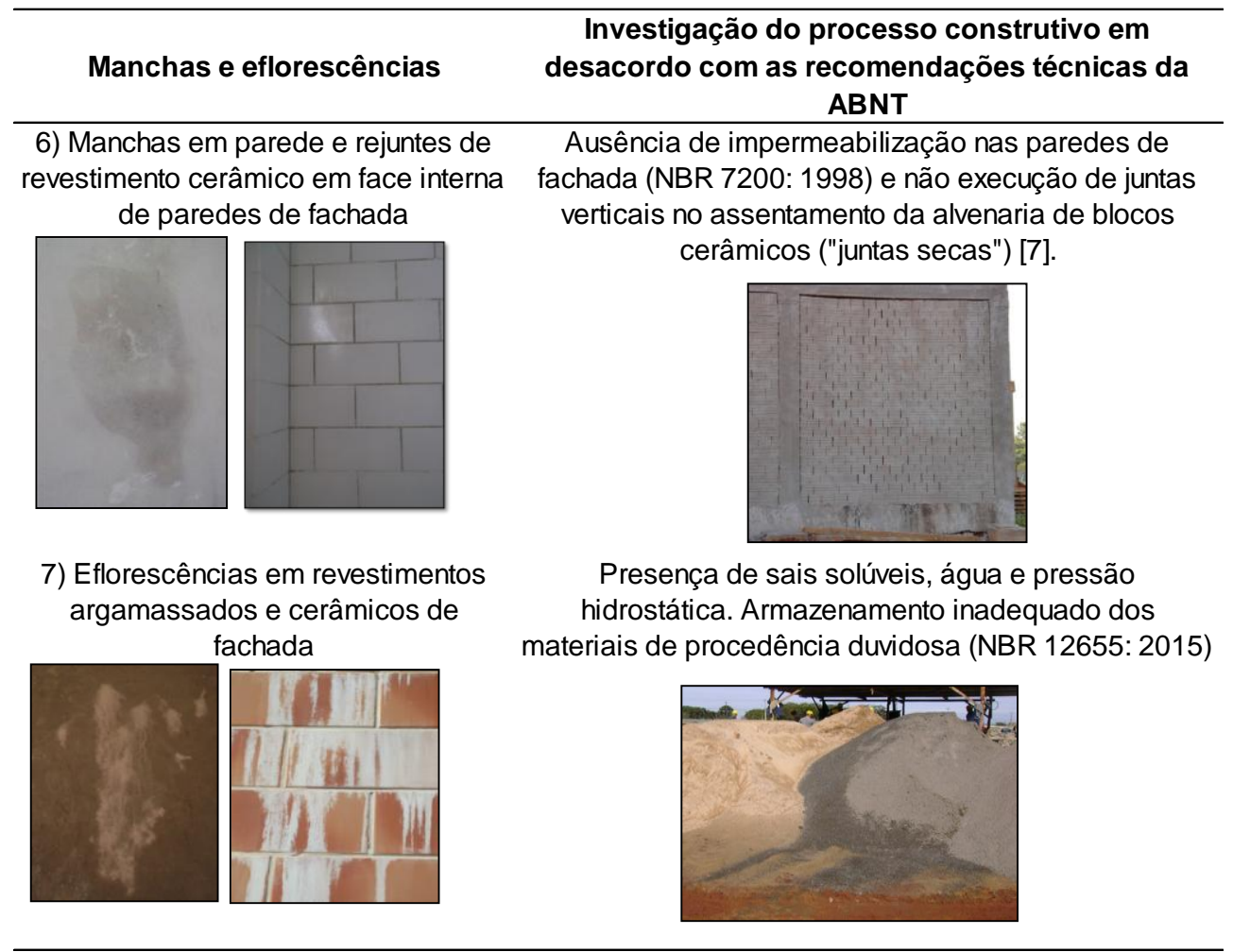

\subsubsection{Fissuras em elementos estruturais}

Foram identificadas ainda, fissura verticais em elementos estruturais como vigas de concreto armado conforme mostra a tabela a seguir

Tabela 3: Fissura em elementos estruturais

\begin{tabular}{cc}
\hline Tipo de fissura & $\begin{array}{c}\text { Investigação do processo construtivo em } \\
\text { desacordo com as recomendações técnicas da } \\
\text { ABNT }\end{array}$ \\
\hline
\end{tabular}

8) Fissuras verticais em vigas

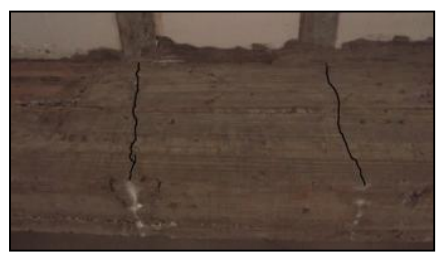

Alteração do tipo de laje, de bidirecional para unidirecional, sem atualização do projeto estrutural das vigas e pilares.

A laje nervurada treliçada bidirecional possuia nervuras em duas direções ortogonais entre si, permitindo maior distribuição dos esforços nos apoios, os quais se dão em todas as direções. Já na laje nervurada treliçada unidirecional, as nervuras eram dispostas em uma única direção, normalmente na direção de menor vão, distribuindo os esforças entre as vigotas em apenas uma direção e em apenas dois apoios [11,12]. A troca do tipo de laje, de bidirecional para unidirecional, induziu uma alteração no carregamento das vigas, ocasionando a redistribuição das cargas na estrutura. 


\subsubsection{Infiltração em lajes de cobertura}

Em obra, constatou-se a inexistência de projeto de impermeabilização com as especificações detalhadas dos sistemas de impermeabilização a serem utilizados na obra, sendo sua localização prevista apenas em planilha contratual, porém sem quaisquer detalhes construtivos ou especificação técnica.

Tabela 4: Manchas de bolor

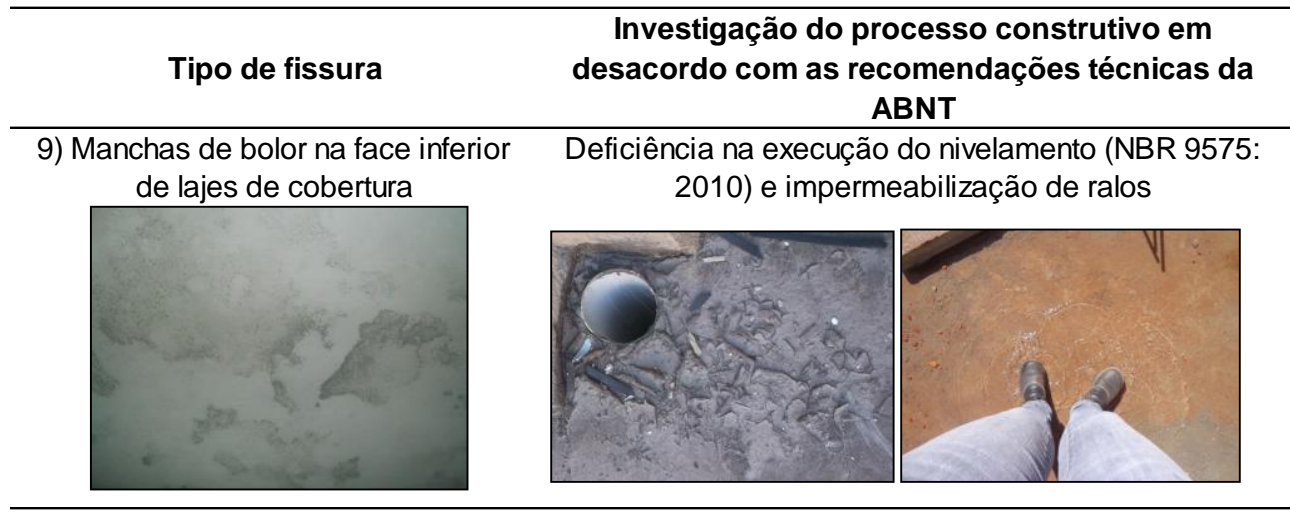

O sistema de impermeabilização empregado nas lajes de cobertura foi borracha líquida aplicada sobre a superfície de concreto, com rolo de pintura, em duas demãos, diretamente sobre a capa da laje, não sendo identificada a execução de camada de proteção mecânica como recomenda Vacchiano [13]. Verificou-se ainda, a ineficiência da drenagem e acúmulo de água devido ao pouco caimento da laje e falta de cuidado na impermeabilização de ralos.

\subsubsection{Corrosões em armaduras}

Tabela 5: Corrosões

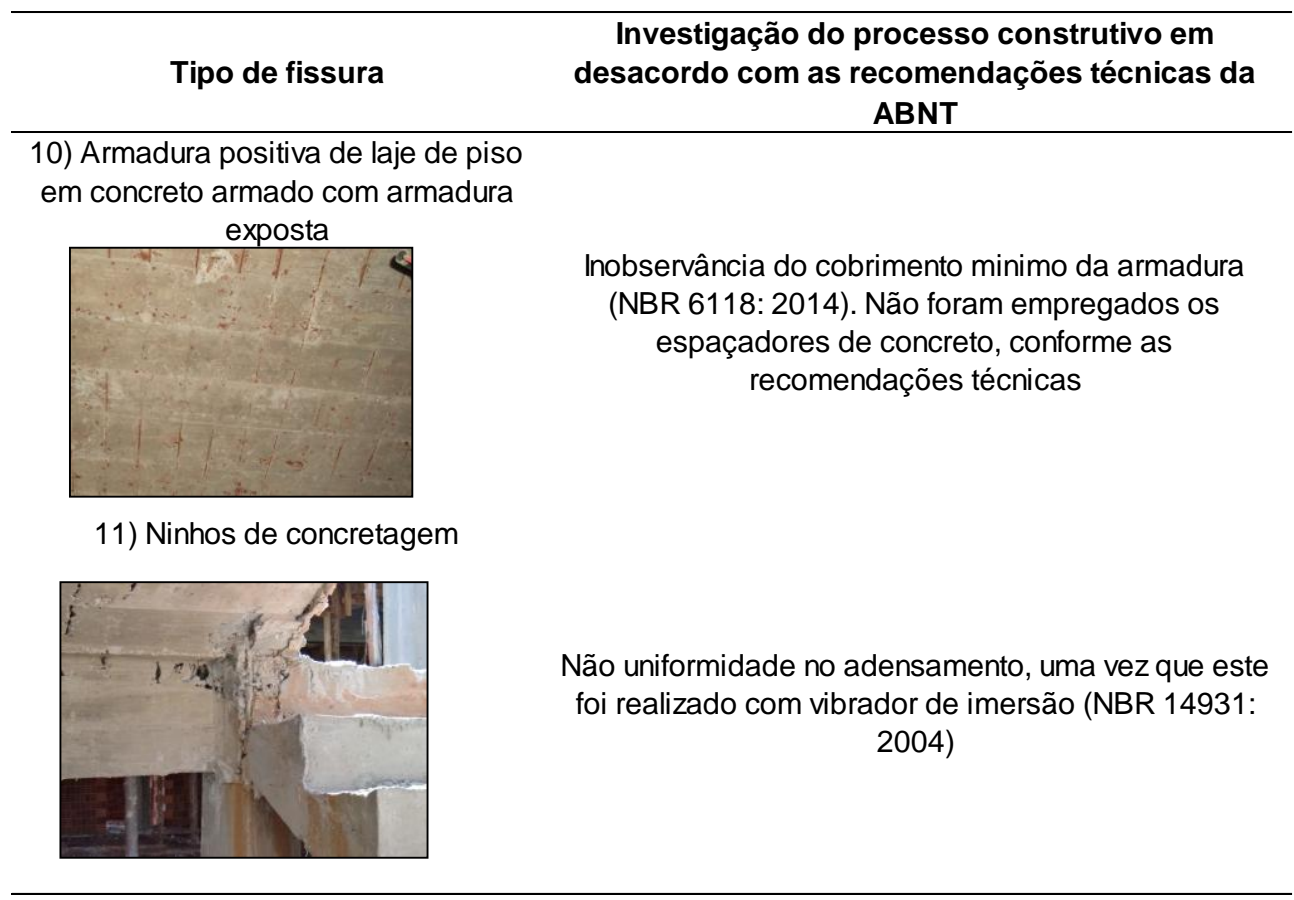


FIGUR, N.E.; FURLAN, G.C., MANIFESTAÇÃO DE PATOLOGIAS E IMPERFEIÇÕES CONSTRUTIVAS: ESTUDO DE CASO EM OBRA PÚBLICA NA CIDADE DE TOLEDO-PR. $3^{\circ}$ Simpósio Paranaense de Patologia das Construções (30 SPPC), artigo 3SPPC1001, pp. 1 - 12, 2018. DOI: 10.4322/2526-7248.001

Em determinados elementos estruturais, como vigas e escada de concreto armado, contatou-se armaduras dispostas próximo das superfícies quando da sua colocação nas formas, permanecendo sujeitas à presença de água e ar, podendo levar à um processo de corrosão dessa armadura como observado por Thomaz [6].

\subsubsection{Infiltrações em esquadrias}

Identificou-se umidade próxima à região da contraverga devido a deficiência na vedação aliada à falta de declividade do peitoril, bem como a falta de barreira de vedação na face superior do peitoril que evite a entrada de água. Já na face superior, a ausência de declividade favorável que impeçam o escoamento da água para a face interna da edificação aliada a ausência de vedação.

Tabela 6: Manchas infiltração em regiões próximas à esquadrias

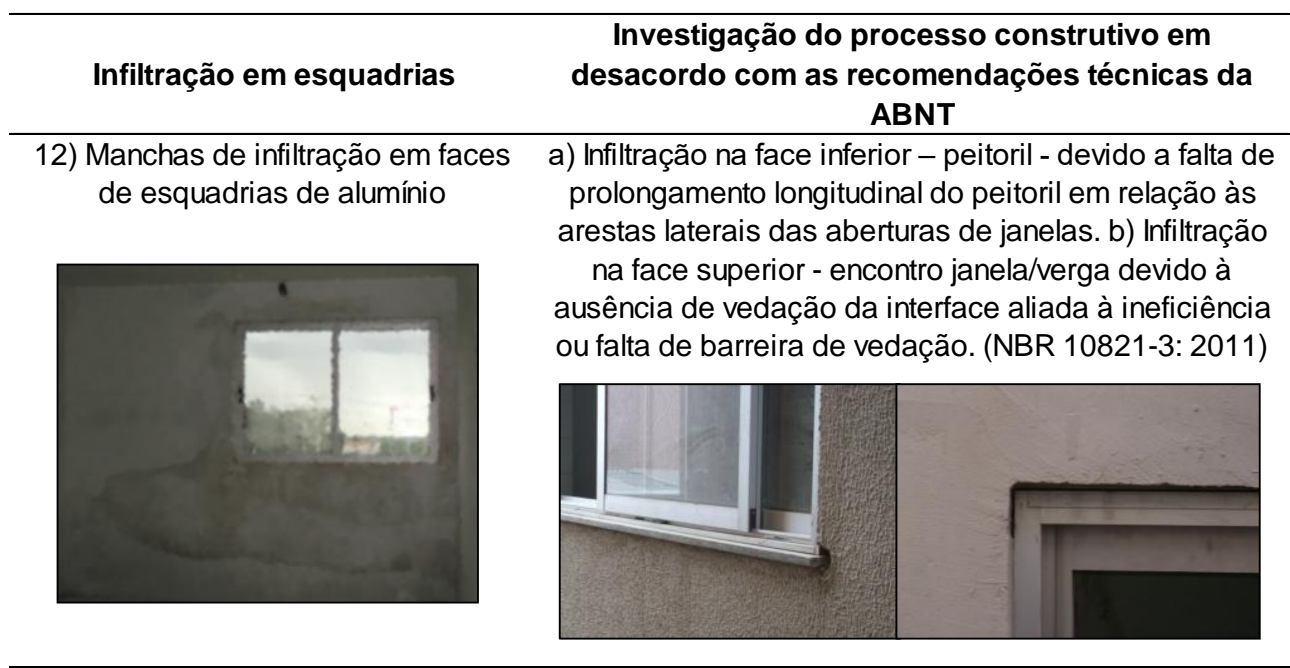

\subsubsection{Fissuras em forro de gesso}

Tabela 7: Trincas em forros de gesso.

\begin{tabular}{cc}
\hline Fissura em forro de gesso & $\begin{array}{c}\text { Investigação do processo construtivo em } \\
\text { desacordo com as recomendações técnicas da } \\
\text { ABNT }\end{array}$ \\
\hline $\begin{array}{c}\text { 13) Fissuras em forros de gesso } \\
\text { comum em cantos de parede e } \\
\text { paralelas à junta de dilatação da } \\
\text { estrutura }\end{array}$ & $\begin{array}{c}\text { Ausência de juntas de dessolidarização e de } \\
\text { movimentação entre a parede e o forro [6] , utilização } \\
\text { de pendurais na diagonal imprimindo esforços } \\
\text { horizontais nas placas [14] e inexistência de juntas de } \\
\text { dilatação nos forros [15] }\end{array}$ \\
FUNTA ESTRUTURAL & Forro \\
FORRO &
\end{tabular}

Grande parte do revestimento do teto, da obra em estudo, foi feito com placas de gesso de 0,60 x 0,60cm encaixadas uma a uma por sistema macho e fêmea, com fixação por arame galvanizado preso a laje (pendurais). 
De modo a prevenir as trincas em forros de gesso, Yazigisi [14] menciona que é necessário permitir a livre movimentação do mesmo. Para tal, recomenda a execução de juntas de dessolidarização entre o forro e as paredes ou elementos da estrutura, permitindo que estes movimentem de maneira diferencial. O mesmo autor prevê que os arames que sustentam as placas de gesso, devem ser fixados sempre a prumo. Quando não for possível, utilizar outro tirante na diagonal oposta, de modo a não criar esforços horizontais nas placas, uma vez que o gesso é um material que apresenta baixa resistência à tração e ao cisalhamento. Em forros extensos, porém, devem ser realizadas juntas de movimentação ou dilatação intermediárias.

\subsubsection{Fissuras em piso de granilite}

Tabela 8: Trincas em piso de granilite

\begin{tabular}{cc}
\hline Fissura em piso de granilite & $\begin{array}{c}\text { Investigação do processo construtivo em } \\
\text { desacordo com as recomendações técnicas da } \\
\text { ABNT }\end{array}$ \\
\hline 14) Fissura em piso granilite & $\begin{array}{c}\text { Propagação de fissuras oriundas da má execução de } \\
\text { juntas de concretagem de piso de concreto, } \\
\text { intensificada pela ausência de uma camada de } \\
\text { dessolidarização entre revestimento/base [16]. }\end{array}$ \\
JUNTA DE \\
CONCRETAGEM
\end{tabular}

A solidarização dos revestimentos em granilite ocorreu após o revestimento ter aderido ao substrato. Neste caso, quando há perturbações ocasionadas tanto pelo granilite como pelo substrato, podem ocorrer tensões na ligação entre eles que levarão à formação de fissuras. Estas por sua vez, podem prolongar-se tanto do granilite para o substrato, como do substrato para o granilite [16].

\subsection{Imperfeições}

Além das anomalias identificadas no item anterior foram observadas ainda, evidenciando a má qualidade da obra empregada, imperfeições como paredes fora de prumo (Fig. 2a) e esquadro (Fig. 2b).

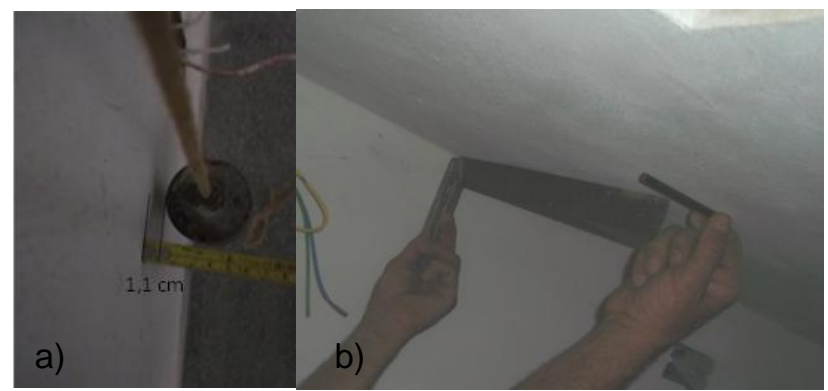

Figura 2: Defeitos em paredes de alvenaria a) Parede fora de prumo. b) Parede sem esquadro 

3SPPC1001, pp. 1 - 12, 2018. DOI: 10.4322/2526-7248.001

Em visitas ao canteiro de obras verificou-se que, em grande parte, a execução da alvenaria era realizada sem o emprego de equipamentos e ferramentas que auxiliassem na determinação, tanto do alinhamento horizontal como do vertical, conforme recomendações da NBR 8545:1984 (Fig. 3).
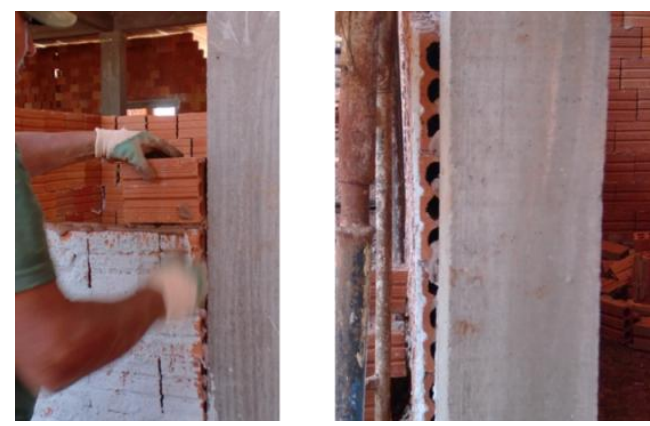

Figura 3: a) Assentamento de alvenaria sem o emprego de ferramentas adequadas.

b) parede concluída

Em decorrência de tais falhas, em determinados locais, na intenção de corrigi-las, optou-se por engrossar a camada de emboço, como é possível observar na (Fig. 4), onde a espessura do emboço é de cerca de $9 \mathrm{~cm}$, extrapolando os limites estabelecidos pela NBR 13749:2013 (5 $\leq$ e $\leq 20 \mathrm{~mm}$ para parede internas e $20 \leq \mathrm{e} \leq$ 30 para paredes externas) resultando, além do desperdício de material, inserção de cargas não previstas no dimensionamento da estrutura.

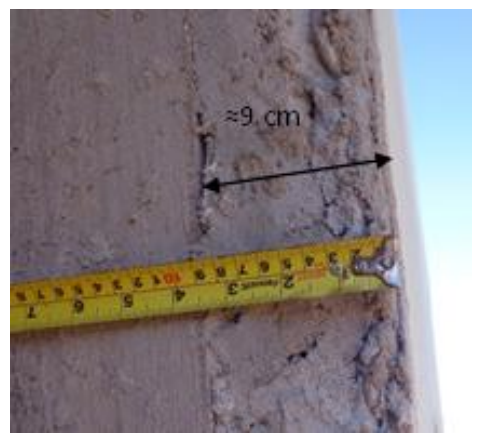

Figura 4: Emboço em parede de alvenaria em desaprumo

A não observância do prumo e nível das paredes e revestimentos, principalmente nas laterais de vãos, dificultou a instalação dos caixilhos das esquadrias, especialmente de madeira. Já paredes fora de esquadro interferem na execução do piso cerâmico, exigindo corte do mesmo condizente com o alinhamento da parede, e dificuldade na disposição dos móveis.

Outro elemento construtivo, no qual foram identificadas imperfeições, foram os pisos cerâmicos em boxes de banheiros (Fig. 5).

Observou-se que a tanto o caso de lajes pré-moldadas de pisos superiores, como em substratos de concreto em pisos térreos, não fora executado camada de regularização. Na tentativa de corrigir o problema, buscou-se, com a própria argamassa de assentamento de piso fazer o caimento do piso para os ralos. As argamassas de assentamento, porém, em comparação com o concreto ou argamassa de cimento e areia, apresentam menor consistência quando da adição da água, não permitindo o posicionamento desejado das peças. Como resultado, 

3SPPC1001, pp. 1 - 12, 2018. DOI: 10.4322/2526-7248.001

além do consumo excessivo de material devido à grande espessura exigida da camada de argamassa para assentamento, não se obteve o resultado esperado, como verificado.

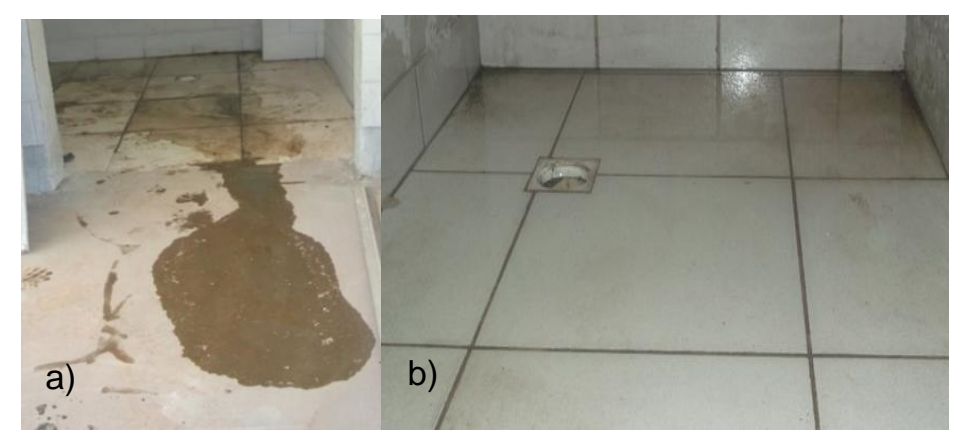

Figura 5: Caimento inadequado em piso cerâmico em boxes de banheiros

\section{Considerações finais}

Os resultados mostram a importância dos cuidados a serem tomados na fase de execução e especificação dos serviços no canteiro de obras, especialmente em relação à mão de obra, uma vez que, de forma unânime, todas as falhas identificadas foram relacionadas ao não seguimento das normativas para a correta execução de cada elemento construtivo, o que mostra a baixa qualidade da mão de obra e/ou a falta de treinamento da mesma. Retrabalhos e recuperações consomem recursos financeiros com mão de obra e desperdícios de materiais que, poderiam ser inteiramente evitados.

As falhas identificadas mostram ainda que, além da falta de capacitação da mão de obra, não havia eficiente comando e fiscalização de equipe por parte do mestre de obras e/ou do engenheiro civil, os quais deveriam orientar e exigir do operário a correta execução dos serviços.

Conclui-se que, o critério de contração de obras públicas no Brasil, é ineficiente, pois o que prevalece, em sacrifício da qualidade das obras, é a máxima de redução de custos por parte das empresas licitadas que, para tal, acabam optado pela contratação da mão de obra barata e, em grande parte, sem qualidade. Ou ainda, no emprego de materiais de baixa qualidade, como verificado principalmente em relação aos blocos cerâmicos, visivelmente de baixa qualidade, o que acaba contribuindo para a propagação das falhas construtivas cometidas pela mão de obra.

\section{Referências}

[1] FABRICIO, M. M. Projeto Simultâneo na construção de edifícios. Tese de Doutorado, Escola Politécnica, Universidade de São Paulo, São Paulo, 2002.

[2] ALVES, C. A. dos S. O princípio da eficiência e o critério do menor preço na licitação pública, 2014. Monografia (Bacharel em Direito), Graduação em Direito do Centro de Ciências Jurídicas da Universidade Federal de Santa Catarina, Florianópolis, 2014. 

3SPPC1001, pp. 1 - 12, 2018. DOI: 10.4322/2526-7248.001

[3] IANTAS, L. C. Estudo de caso: Análise de patologias estruturais em edificação de gestão pública, Monografia (Título de Especialista em Construção de Obras Públicas) - Curso de Pós Graduação em Construção de Obras Públicas, Universidade Federal do Paraná, Curitiba-PR, 2010.

[4] OLIVEIRA, D. F. Levantamento de causas de patologias na construção civil. Projeto de Graduação (Curso Engenharia Civil), Escola Politécnica, Universidade Federal do Rio de Janeiro, Rio de Janeiro, 2013.

[5] HELENE, P. R. L. Manual para reparo, reforço e proteção das estruturas de concreto. 2a ed., 3aㅡ reimpressão (jan. 96). São Paulo: Editora PINI, 1992.

[6] THOMAZ et al. Trincas em edifícios: causas, prevenção e recuperação. São Paulo: Pini, c1989. 194 p.

[7] THOMAZ, E.; HELENE, P. Qualidade no projeto e execução de alvenaria estrutural e de alvenarias de vedação em edifícios, São Paulo: EPUSP, 2000.

[8] DUARTE, R.B. Fissuras em alvenarias: causas principais, medidas preventivas e técnicas de recuperação. Porto Alegre: CIENTEC, 1998. Boletim Técnico n. 25.

[9] SCARTEZINI, L. M.B. Influência do tipo e preparo do substrato na aderência dos revestimentos de argamassas: estudo da evolução ao longo do tempo, influência da cura e avaliação da perda de água da argamassa fresca. Dissertação (Mestrado em Engenharia Civil). Universidade Federal de Goiás, Goiânia, 2002.

[10]MAGALHÃES, E. F., Fissuras em alvenarias: configurações típicas e levantamento de incidência no Estado do Rio Grande do Sul. Dissertação (mestrado em engenharia) - Universidade Federal do Rio Grande do Sul, Porto Alegre, 2004, p. 180.

[11]BARBOZA, M. R. Concepção e análise de estruturas de edifícios em concreto armado. Relatório (Iniciação Cientifica). Universidade Estadual Paulista, Bauru, São Paulo, 2008.

[12] CUNHA, M. O. Recomendações para projeto de lajes formadas por vigotas com armação treliçada. Dissertação (Mestrado). Escola de Engenharia de São Carlos da Universidade de São Paulo, São Carlos, 2012.

[13] VACCHIANO, I. Manual Prático do Mestre de Obras, 3ํe ed.V.10, 2014.

[14] YAZIGI, Walid, A técnica de Edificar, Editora: Pini: SindusCon - SP, 1998.

[15] JOHN, V. M. Como evitar as trincas e fissuras nos forros...Piniweb. 12 dez.2000. Disponível em: http://piniweb.pini.com.br/construcao/noticias/comoevitar-as-trincas-e-fissuras-nos-forros-e-pre-moldados-83990-1.aspx. Acesso em: 09/09/2015. 